\title{
«Huge, Disgusting, Corpulent, A-Hundred-Throats»: a Philosophical Study of the Fence and Other Monsters (Review of the book Savchuk V.V. Fence as a Balance of Forces. St. Petersburg: Publishing house Academy of Culture Research, 2021. - 249 p.)
}

\section{Konstantin A. Ocheretyany}

St. Petersburg State University. Saint Petersburg, Russia. Email: kocheretetyany[at]gmail.com

\section{Abstract}

The text is a contemplation review of the new book by V.V. Savchuk. Fence as a balance of power. (St. Petersburg: Publishing House “Academy of Culture Research", 2021. - 249 p.). The book raises a wide range of problems: the world as an extension of the skin, cultural rhythms of the collective body, principles of building trust and openness, mechanisms of psychological isolation and social distancing, current forms of environmental reflection and art practice. The fence turns out to be one of those limiting things, after the invention of which it is not clear how to think of culture without it. An excursion into the author's thought is given, the logic of the narrative being built is commented to reflect on the embarrassing omnipresence and inevitability of the fence. How did culture end up crucified on the fence? When is the fence not a source of comfort, but of excess discipline and increasing anxiety? What is intimidation fraught with? All these questions are outlined and deeply investigated by the author, while the task of this text is to maximize attention both to the book and to the problem. In other words, start a productive dialogue about fences - which, paradoxically, has hardly been noticed in humanistic research.

\section{Keywords}

Balance of Power; Collective Body; Building Trust; Rubbish; Alienation; Topological Reflection; Performativity; Thanatology; Psychedelic Drift; Downside of Transparency) 


\section{«Обло, озорно, огромно, стозевно...»: философское исследование забора и других чудовищ (рецензия на книгу Савчук В.В. Забор как равновесие сил. СПб.: Издательство «Академия исследования культуры», 2021. - 249 с).}

\section{Очеретяный Константин Алексеевич}

Санкт-Петербургский государственный университет. Санкт-Петербург, Россия. Email: kocheretetyany[at]gmail.com

\section{Аннотация}

Текст представляет собой рецензию-соразмышление на новую книгу Савчука В.В. Забор как равновесие сил. (СПб.: Изд-во «Академия исследования культуры», 2021. - 249 с.). В книге поднимается широкий спектр проблем: мир как продолжение кожи, культурные ритмы коллективного тела, принципы формирования доверия и открытости, механизмы психологической изоляции и социального дистанцирования, актуальные формы экологической рефлексии и арт-практики. Забор оказывается одной из тех предельных вещей, после изобретения которой непонятно как мыслить культуру без нее. Дается экскурс в мысль автора, комментируется логика выстраиваемого повествования для продумывания смущающей вездесущности и неотменимости забора. Как культура оказалась распята на заборе? Когда забор оказывается не источником комфорта, а избыточной дисциплины и увеличивающихся тревог?

Чем чревато устрашение? Все эти вопросы намечены и глубоко исследованы автором, задача же данного текста - привлечь внимание равно как книге, так и к проблеме. Иными словами начать продуктивный диалог о заборах - который парадоксальным образом в гуманитарных исследованиях почти не был замечен.

\section{Ключевые слова}

равновесие сил; коллективное тело; формирование доверия; мусор; отчуждение; топологическая рефлексия; перформативность; танатология; психоделический дрейф; оборотная сторона прозрачности 


\section{Почему забор?}

«Я победил мрамор и сделал его пластичным, как воск...» - будто бы сказал Джованни Лоренцо Бернини о своей скульптуре «Похищение Прозерпины» (1621-1622). «Я сумел материализовать ритм культуры, найти предельное воплощения ее мерам и брешам, границам и переходам, колебаниям и сопротивлениям; когда я удержал вещество материализованного ритма культуры понял, что держусь за забор» - так мог бы сказать Валерий Савчук со свойственной ему иронией о сделанном глубоком открытии. Автор предлагает вспомнить о предельных вещах: не только о таких как эрос, полемос и танатос (без которых - ничего, и с которыми непонятно что делать), но о подобным веревке, ложке, молотке, колесе, ножницах, книге, по Умберто Эко, который заметил: «после того, как они были изобретены, ничего лучше уже не придумаешь» (Карьер, Эко, 2010). Забор - предельный объект, парадоксальный объект: без него - ничего, отсутствие всех меток, с ним - непонятно, что делать и после того, как он изобретен уже нет пути обратно. Если, например, Эрнест Ренан предлагает отважиться на мысленный эксперимент и, изъяв в воображении из европейской культуры идею христианства подумать, что вообще от нее останется (Ренан, 1990, с. 349), Валерий Савчук после захватывающего путеводителя в мир заборов оставляет читателя с мыслю: «А что вообще было если бы вдруг заборы исчезли?» Редко, когда удается зафиксировать материальную выраженность рефлексивных ритмов в культуре столь полно и на столь глубоко утопленным в бессознательное привычкой объектах. Конечно, можно вспомнить похожие проекты Д. С. Лихачева о семантике садово-парковых стилей, где сад являет мирочувствование эпохи (Лихачев, 1998), или камень и его освоение для выражение духовных стремлений эпохи у Жоржа Дюби (Дюби, 2002), а также императив Жиля Делеза: «экран может быть мозгом» (Делёз, 2004, с. 195) - но, список подобных решительных обобщений всегда слишком мал: он требует эрудиции, воли, отваги, отсутствие академической зашоренности, чувства. Вопрос о заборах, иными словами вопрос с головокружительным метафизическим расширением. Мы предпочитаем искать в заборах лазейки, возводить или обходить их, рвать о них одежду, биться головой - но это не приводит к тому, что мы их замечаем. Настало время вместе с автором подумать о заборах в трех модусах: помыслить забор как эрос (т.е. рождение и поддержание жизни), забор как полемос (т.е. как формы борьбы за престиж, признание, значение), забор как танатос (поставить к стенке забора и обрести последнюю ограду или точнее оградку).

\section{Забор как Эрос}

Забор для коллективного тела - то же, что кожа для тела индивидуального. Змея в течении жизни выбрасывает кожу, человек в течении жизни в нее 
входит. Плетение кожи - эрос на анатомическом и символическом уровне сердце, ставшее внешним. Валерий Савчук начинает с необходимости посмотреть в сердце культуры и сменить оптику. Не в том простом смысле что нам не хватает инструмента, сосредоточенности созерцания и свежести взгляда. Чем больше мы стремимся с помощью технологий охватить взглядом, тем меньше это затрагивает нашу кожу - вызывает аллергию, мурашки, хоть какоето чувство затронутости миром. Над миром мы парим, но в нем не живем - его не касаемся, им не затронуты. Или просто забыли об этом? Отсюда, предлагаемый автором рецепт: вообще отказаться от взгляда и вчувствоваться в то, как врастают в собственную кожу, переключиться на тело, его привязки, связи, укорененности. Легко можно реконструировать рождение новоевропейской рациональности из оптических иллюзий: laterna magica иезуитов и проекции тени для овладения коллективным воображением (Киттлер, 2009); визуализация природы, посредством новых артефактов, в экспериментах (столб Торричелли, вакуумный насос Бойля и т.д.) (Shapin, Schaffer, 1985) как претендующее на универсальность средство убеждения, прямая перспектива и возникшая благодаря ей оптическая согласованность, где даже воображаемые объекты предстают в согласии с реальными правилами (что конечно привет к секуляризированному взгляду и расколдовыванию мира, а также к сопутствующим разочарованиям), печатный станок и легко доступная обозримость эпистемических образцов в изображениях, схемах, проекциях иными словами универсально-тиражируемые неизменяемые мобильности (Латур, 2017, с. 95-156). Но в тот самый момент, когда разум обретает глаз он тут же лишается тела, привязок к земле, оптические иллюзии оказываются идеологическими иллюзиями, средством левитации, письмом слепых, предназначенных зрячим. Валерий Савчук предлагает уйти от оптических констант в работе разума - от всей игры метафор и метонимий, стимулирующих (или скорее, канализирующих) наше мышление к трансценденции и обратиться к цельной включенности, к телесной вовлеченности, к живой связи к топологической рефлексии исследующий забор как кожу, испещренную эрогенными зонами (которые в то же время являются зонами боли). «Стремясь к чистоте рефлексии, трансцендентальный субъект неумолимо отделял себя от ландшафта и климата, от политики и эстетики, а в конечном итоге и от совокупности проблем, включая экологию, демографию и медиакультуру данной местности» (здесь и далее, где иитируется рещензируемый автор ссылки даются по предмакету книги, выходящей в самое блиюайшее время и есть слабая вероятность, что при издании странищы будут +/- смещены, c. 16). Пока чистый разум видел в теле нечистую силу - бессознательное, витальное, дорассудочное или даже доорганическое... оказалось, что необходимо вернуться к неорганическому - к материальному пределу мысли. Зигмунд Фрейд обнаружил, что жизнь - окольный путь к смерти, а организм приходит к гомеостазу не напрямую, но путем постепенного балансирования 
энергий и выстраивания преград - символов, образов, текстов, формул, заборов (все это - затяжной трип, Todestrieb). Колыбель тогда меняет значение - это не начало жизни, а удержание ее утекания, растрачивания, замедление смерти в ритме сна. Забор - первая колыбель как сновидческая ловушка, удерживающая жизнь и замедляющая смерть. Мысль, культура, человек существуют внутри этой колыбели - материальных пределов, но задача жизни взять на себя даже неорганические условия - замедлить влечение к смерти и забор, возможно, первый работающий замедлитель, который стал проводить и другие ритмы - уплотнения, интенсификации, ускорения, увеличения пластичности жизни. Задолго до того, как люди поняли, что космос не есть порядок, а только стремление к нему, а сам порядок как космическое равновесие является остыванием жизни, они уже сопротивлялись этому процессу внутри заборов - там, где очаги и храмы, дома и животные, там, где даже запахи дерьма являются запахами близко подступившей (и медленно уходящей) жизни.

Уходя в землю забор заземляет мысль: «Опираясь на опыт мышления тела, на опыт отношения к окружающему миру как к продолжению кожи, рефлексия неумолимо обретает топологические черты» (c. 20). Забор замедляет работу смерти, интенсифицирует и углубляет процессы жизни, возможно даже впервые обращает ее на саму себя. Согласно автору, первые заборы строили не только для того, чтобы кто-то не пришел к человеку (зверь, дух, чужак, мертвец), но для того, чтобы человек не ушел от самого себя (и не стал, соответственно, зверем, духом, чужаком, мертвецом) - чтобы жизнь не распылялась, а возвращалась. Забор - есть равновесие сил, защищая жизнь от распыления в пространстве, а также сопротивляясь имплозии, предельному сжатию становится мнемонической осью коллективной суггестии, мембраной обращающий жизнь на саму себя, в рост, развитие, совершенствованию как отказу от альтернатив - на право обещать, на боль быть человеком, т. е. каждый день приходить в себя, просыпаться в тех же стенах, в том же теле, в том же сознании, к той же работе, в тех же культурных метках, он ограничивает как рассеяние, так и имплозию. Родовое тело старше тела индивидуального и до того как у человека появилось чувства тела (как своей ноши) у него было чувство, рода, территории, до собственной кожи (культуры вины и стыда, социальной дистанции и поведенческой дисциплины) уже был забор как питающая мембрана. Библия рассказывает, что Каин убийца Авеля - основатель городов. При этом ему в качестве наказания было предписано вечное скитание. Противоречие латинской Вулгаты (где Каин - vagus et profugus)

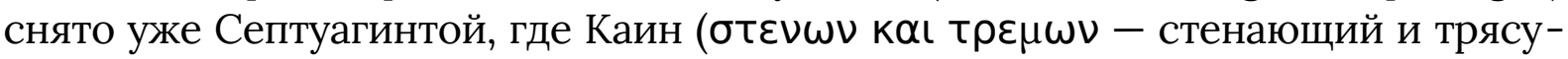
щийся). Каин основатель оград... могильных, городских, сам скован оградой и при этом постоянно перемещается вдоль нее, во времени, в культуре, в сознании. Город колеблется в своих границах, но питается волнами собственных энергий. Земля забранная - интенсифицирует духовные и культурные процессы. Сравним, описанное с диалогом Платона «Политик»- 
где Кормчий, управитель Космоса, оставляет кормило и космос начинает вращаться под воздействием судьбы и врожденного вожделения, следовательно вырождается, животные дичают, люди запираются в городах. Забор здесь взятие судьбы в свои руки, отказ от ухода от себя ради продвижения в себя, пусть это продвижение и окажется блужданием, стенанием и тряской - все это муки рождения. Раньше эрос означал стремление вовне, задача забора - суггестия, система отражений, взятие эроса на себя - напомним, что лабиринт, например, - это материнское лоно, а забор от глагола «забрать», далее из праслав. *bьrati имеет значение бремени, беременности, рождения.

Забор - любовное собирание стихий в коллективном теле, реорганизация неорганических условий для рождения и возрождения органичных форм взаимодействия, взаимопонимания, согласия - для новых форм жизни. И здесь интересны телесные аспекты теории заборов, которые прослеживаются автором в сопутствующих главах («Забор пространства», «Забор как мембрана»): 1) забор - суггестивен и аттрактивен: им были зачарованы еще до изобретения сцены и экрана; 2) забор - эротичен, он соблазняет и обещает; 3) забор - очаг жизни, плавильный тигель для человеческого материала, рождающее лоно. За забором, - «безводные пески и дикие звери», или: «Болота Мрака», или: «Скифские морозы», или: «Ледовитое море» (Плутарх, 1961, С. 5), молчание о котором я не знаю и которое не хочет знать обо мне - там может лежать желание и скитание, приключение и надежда, но они обладают перформативным характером и любой, отваживающийся на путь не сможет сохранить свои навыки неизменными - не сможет вернуться за забор тем каким был. Парадоксальным образом люди чаще выходят за забор не потому, что хотят вообще покинуть границы, а потому что хотят оказаться внутри других оград, переродиться - там, где техники тела и поведенческие стратегии, активности и мобильности вызывают больший соблазн. Забор, может быть, не только любовными объятиями, определяющими контур коллективного тела, но и предметом ревности, осмеяния, осквернения, насильного овладения - полемосом.

\section{Забор как Полемос}

В 1957 году историк Эрнст Канторович (Канторович, 2015) перевел проблему телесности в область того, что он сам охарактеризовал «политической теологией» показав, что юристы, историки и теологи Средневековья и раннего Нового времени фактически удвоили короля (по аналогии с богочеловеческим телом Христа) понимая его как смертного индивида и как сакральную институцию; тело короля с одной стороны продукт природы и с другой стороны - ритуалов и церемоний. В 1649 г., когда Палата общин казнила природное тело короля Карла I Стюарта, она же унаследовала его политическое тело. Но, что, если тело короля уже прежде казни реального 
монарха было символически распято на заборе - иначе говоря, что, если забор в своей форме - расширения, удлинения, плетения, создавал (в)не-человеческое сакральное тело, которое было до императора, короля, монарха, сюзерена? Отсюда проблема символики забора, воображения им улавливаемого или провоцируемого, а также сопутствующих императивов и перформативов. Ведь даже в брешь забора не надо заглядывать, чтобы толкнуться с собственным гипостазированным воображением, приближаясь к нему, чтото уже происходит в нас самих - что-то амбивалетно охватывающее наше присутствие. Так соглядатай, заглянувший за забор, выскажет лишь неопределенное: «Да... Живут, же, прости Господи, тьфу!». В книге «Эмоциональная логика капитализма» Мартейн Конингс принимает попытку использовать перформативную теорию иконического знака в применении к деньгам, представив денежный знак не в качестве социального конструкта или коллективной иллюзии, а в качестве означающего, содержащего в себе полноту присутствия (Konings, 2015). Забор также не производит иллюзии задних миров, т.е. ни к чему не отсылает, а скорее интенсифицирует присутствие, т.е. обладает коллоссальной аффективной и перформативной силой. Забор не знак но чистое присутствие: «Любая материальная ограда включает момент нематериальный (символический, до-правовой, мифологический), оправдывающий право владеть этой землей, господствовать над людьми, на ней живущими, и, напротив, любая нематериальная ограда с неизбежностью овеществляется» (c. 29). Забор сам может создавать величие призрачной королевской гробницы - которую хотят разграбить и бояться проклятий. Ведь то, что вызывает любовь, воспламеняет и ревность. Забор даже как неорганический, мертвый

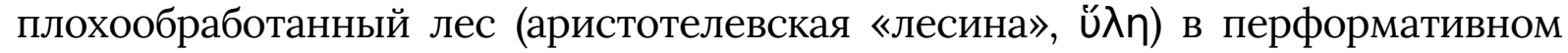
символическом измерении интенсифицирует присутствие и становится формой форм, душой, жизнью - забирающий все внимание и силы, пробирающей кожу булавочными иглами ужаса, выливающийся в чувство настоящего, подлинного - проливающийся татуировкой, открывающийся раной, кровью. Забор становится экраном полемоса, пунктом обменом жизни на смерти, жертвы на жизнь: возвышенным одновременно в вещественно-количественном и в мистико-чувственном смысле, которая через традицию от Лонгина до Канта становится экзистенциальной открытостью в поздних философских изводах. Чем он выше, чаще, причудливее - тем больший жар вокруг сердца он разжигает. Не случайно одна из древнейших историй человечества - история осажденного (и обреченного) города: в заборе сплетены борьба и труд - два ключевых вида полемоса, драйвера социокультурных интрефейсов: причем кажется, что чем больше силы следует приложить для преодоления забора - тем большим количеством труда можно пренебречь после. Изначальный импульс осады - пренебрежение к труду создателей преграды. Труд облагораживает человека, но он же может превратить его в животное. Чем больше забор походит по форме к стене, чем дольше он обустраивается, чем больше сил он требует - тем больше он отчуждает, нежели объединяет - 
уходят поколения, а стена еще не достроена, нужно обслуживание, что вызывает дополнительные тревоги и заботы - исходный Другой превращается уже не в зверя или в Бога, а в призрака, который тем могущественнее, чем дальше, тем влиятельнее, чем менее материален - он вызывает головокружение и чувство потерянности. Те же, кто смотрит на забор извне - полагают найти за ним ослабленных и пресыщенных. Им завидуют, их ненавидят, а сам забор - воспринимают как судьбу несправедливо распределившею (отделившую) блага. Достаточно вспомнить вал Адриана светскую проекцию священного Померия или Великую китайскую стену, которую, по массовым домыслам, видно из космоса (считай - видит сам Космос, ведь она в Поднебесной). А между этими легендарными «заборами» уже кипит великое переселение народов - намечены будущие крестовые походы, личностный мистицизм, географические открытия, технологическая и интеллектуальная революция. Недаром как отмечает историк-баталист Франко Кардини: «Великая Римская империя, окруженная оборонительным валом, - осажденная крепость. На противоположном конце Евразийского континента поднялась Великая стена. Из-за нее другие глаза внимательно и настороженно вглядывались в горизонт. И в них тот же страх» (Кардини, 1987, с.171). Он же добавляет: «В одном из документов, относящихся ко времени крестовых походов, подчеркивается, что при взятии Иерусалима в 1099 г. вместе с живыми на штурм шли и все те, кто погиб в пути» (Кардини, 1987, с. 135), т.е. никогда забор не ослабляет притяжение.

Забор вызывает дрейф - геополитический и психопатологический, о нем мечтают, им грезят, на нем хотят быть распятыми, брешь в нем хотят закрыть своим телом, к нему стремятся и после смерти. Следовательно забор - производит больше эмоций чем понимания, а потому надежнее инспирирует чувство, чем рефлексию и главное из этих чувств - чувство несправедливости, оставленности, незащищенности - начало права. До того, как правовая система (регулятивы к монополизации насилия) появилась в записи - она существовала в качестве заборов. Тяжба, обет, прения действуют даже за гробом и все это как на магнитный полюс направлено в сторону оград, заборов и стен только потому, что они переводят чувство оставленности в форму выставленности. Чем больше тревога, чем более слабы обещания, чем меньше доверия - тем выше заборы и все же - за самым высоким забором видят самую высокую силу, могущество, дисциплину. Дисциплина ведь тоже не есть нечто рассудочное, скорее нечто что надежно определяет практики поведения, до всякого понятия: ее не столько осознают, сколько желают. Следовательно, от забора ждут дисциплины, точнее, чем больше к забору приближаются, тем больше о нем грезят: о расписании, заявленных правилах игры, структурах обмена и иерархической логике. О том, что все тревожащее меня в заборе как воплощенной дисциплине перейдет в то, чему завидуют другие - и даже за мои страхи, неврозы, беспокойство будут бороться другие, если они воплотить эти состояния в заборе. На ленту Мебиуса похож забор 
поскольку тревога, скользящая вдоль него, не меняя стороны легко переходит в зависть: и вот кажется, что там не меньше уверенности, а больше жизни она интенсивней, острее, разнообразнее. В столбах и перекрытиях заборах мерцает действительность, кружит голову и все - выглядит не тем, чем полагалось. Даже мусор появляется вдоль заборов не случайно поскольку мусор есть только там, где намечена иерархия и неравноправие: следовательно, даже то, что выброшено за забор или у забора из меты осквернения, превращается в символ избыточного потребления, пренебрежения к природе и т.д. Забор и осквернить толком не выходит. Любое насилие, он обращает против самого себя и делает его праздностью - все что терзало меня, отражаясь в заборе начинает терзать других. Забор навязывает полемос для распределения тревог, для превращения самой тревоги в знак избранности и престижа. Отсюда амбивалентность укрепленной территории: свободный переход притязания в истязание и обратно. «Крепость или замок, как места особо охраняемого и, следовательно, безопасного укрытия, в зависимости от обстоятельств легко становились узилищем или успешно совмещали одновременно обе функции» (с. 39). Коллективные тела ведь часто образуются, чтобы компенсировать либидинальные энергии: и не обязательно помнить о варварах (будь это гунны или готы) ищущих заборы, которые можно преодолеть и которые их влекут как раз непреодолимостью, не обязательно обращаться и к древним «болельщикам», партии ипподрома в Византии - «зеленых» (посвященные весне и земле), и «синих» (морю, небесам и осени), которые обороняли город, возводили на престол императоров, получали собственные скульптурные изваяния. Достаточно сходить на стадион современный: где стены - это и престиж, и обязательство, и арена, и тюрьма. И в наше время высокие стены стадиона, возводящиеся исключительно в мирных целях - не пропускать без билетов на футбол или иной спортивный праздник, - легко превращают его в концентрационный лагерь под открытым небом. Примером такого превращения был «Национальный стадион» Чили, который «стал тюрьмой на два месяца с 12 сентября по 9 ноября 1973 года. За это время через него прошли от 20 до 40 тысяч человек» (с. 40). Избыток обязательств рождает чувство реальности - и автор удачно находит примеры дематериализованных заборов, таких как чувство дистанции, порядка, ответственности, заборов, которые становятся прозрачными и мобильными, таких как экран смартфона, которым можно закрыться, а также заборов, встроенных в архитектурные формы, предназначенные для публичной коммуникации, релаксации, единения. Однако избыток реальности угрожает перейти в отсутствие возможностей. Комфорт, который мы ищем в капсульных оболочках современности - апартаментах, номерах отеля, рабочих местах, личных автомобилях, аватарах в социальных сетях обратная сторона насилия, поскольку мы все больше обращаемся лишь на самих себя, а значит трудимся только над собой и ведем борьбу только с самими собой: чем больше дематериализуются преграды, тем меньше надежды на их преодоление, тем больше самоограничений налагается 
на поведение человека. Чем более комфортна среда к нему, тем больше он обращен на самого себя, тем чаще малейшие его беспокойства лишь усиливаются, ведь им нет противоречия, альтернативы - блуждая вдоль невидимых оград возвращаются к себе не найдя иного, не находя выхода, разрядки. Благодаря открытым интерфейсам мы закрываемся в себе, углубляемся в себя как в Ад. У тех, кто за забором всего много, но с другой стороны, самые обеспеченные - мертвецы, ведь им ничего не нужно. Обещаемая забором надежность и спокойствие легко переходит в тему вечного упокоения.

\section{Забор как Танатос}

Меньшинства в истории побеждают. Первая победа меньшинства над большинством - победа живых над мертвыми. Претензии живых со временем оказываются важнее чем почтение к мертвым. Неоднократно отмечалось как кладбища перемещаются из центров городов на окраины, а затем и вовсе вне города. Но забывали впрочем, что и у мертвых есть своя «потребительская корзина»: в древних культурах туда входили даже слуги (египетские ушебти, скифские конные войны), во многих современных туда входит небольшой забор. Как отмечает автор даже имя у этого забора компенсаторно-ласковое по отношению к его размеру и значимости - оградка. Сделаем небольшое отступление и вспомним о изображении «Грибного шамана с пчелиным лицом» с плато Тассилин-Аджер которое приводит Терренс Маккена (McKenna, 1993). На первый взгляд кажется, что тело шамана, проросшее грибами схвачено сеткой - на деле же (поскольку архаическая живопись не знает статического изображения) указывается принцип движения: грибы указывают на трансцендирование (они прорастают между мирами), а то, что казалось «сеткой», предстает как экстатическая захваченность, орнаментальный танец, геометрическое галлюционирование.... Грибной шаман захвачен как галлюцинацией геометрическими узорами и орнаментами, сама абстрагирующая деятельность рассудка становится экстазисом, перед силой, концентрацией и чистотой, которого отступают все мифологические образы. Подобным же образом рассуждает Гегель, говоря о мальчике, бросающем в воду камни - он захвачен не кругами на воде, а силой абстракции (Гегель, 1968, с. 37). Забор, ограда - несет в себе эту галлюцинаторную мощь абстракции. Как отмечает автор, орнамент в некоторым смысле - выход забора из самого себя поскольку воплощает воображение пространства вне пространства реального: «орнамент вбирает, возвращая нам и идеальные формы отправления культов, и песни и танцы, и движение рук, берущих холодное оружие, и особенности обхождения данного народа с орудиями труда» (с. 70). Ограды, решетки, орнаменты - таким образом завораживают абстракцией сильнее чем наркотик фантазмами. Связанно это прежде всего с тем, что абстракция - это повторение, правило, регулярность, место вне места. Выселенность мертвого, а также (как отмечает автор), частое 
бесправие и неустроенность при жизни компенсируется их включением в интеллигибельный мир порядка и правил через регулярность и обязательность забора; территория мертвого охваченная оградкой - выражение права на порядок. Но избыточность порядка - также губительна как его отсутствие. Как убедительно показывает автор в соответствующих разделах книги («Стадия геометризации», «Преграда экрана», «Забороустроение жизни»). сегодня мы уже не просто заворожены абстракцией, орнаментом, а чаще видим лишь абстракции. Могильная оградка, орнамент, сеть становится универсальным символом того, как человек обращенный ко всеобщему получает опыт нулевой степени. Если на первых этапах воздействие геометрического жеста на среду позволяла отвоевать ее для жизни, то на поздних подавляет жизнь, отменяя любую непредсказуемость: качество улиц, домов и дорог тяготеет к стандарту, а любой стандарт дезориентирует. Благодаря избытку заборов как претензии всех на свое - право, престиж, комфорт, все оказываются вне всего. Мы оказываемся в месте вне места - в атопии, которая все чаще становится вектором коллективных устремлений. Благодаря избытку заборов - все мы можем оказаться выселены как мертвые. Для мертвого забор, ограда, территория (и сам стандарт) - право на включение в сферу всеобщего, для живого - он становится уже не тем, что подчиняет территорию рассудку, а тем, что лишает воли вследствие монотонности и однообразности. Поразительным образом забор, говорящий о престиже и амбициях, о защите и комфорте, о праве и надёжности - в условиях когда он воплощает пространство вне пространства реального способен заставлять всех молчать. Уже в эссе 1988 года «Постмодернизм и общество потребления» философ Фредерик Джеймсон утверждал, что нарративная теория может быть применена к архитектуре, а то, как люди вынуждены вести себя в этих пространствах - вынужденно превращает тела, движения и действия в игру значений: осанка, походка, взгляд - все это подчинено пространству и соучаствует в воспроизводстве и утверждении нарративных парадигм, которые не столько несут смысл, сколько выступают смысловыми заглушками: рекламными, политическими, экономическими идеологиями (Джеймисон, 2014, сс. 288-309). Но забор как «универсальный уравнитель», превращаясь в архитектурный эталон и оказывая влияние на ландшафт города уже вовсе не определяет ничего, но все лишает определения, делает пустым и безразличным. И у мертвых есть свои правила поведения - этика невмешательства, апатии, всепринятия. Мертвые территории - не обязательно территории, где ничего не происходит, это также и территории, где все происходящее не имеет значения, отклика, отзыва.

Молчание забора - одна из главных проблем, выявляемых книгой, и автор затратил немалые усилия, чтобы разговорить заборы, чтобы не стали они пределом речи, а были началом чуткого внимания. Отсюда темы искусства открытого ритмам коллективного взаимодействия в городской среде, отсюда же и проблемы экологии: возникают сюжеты забора как отбора права 
на движение, взаимодействие, видение, касание, затронутость. Усугубляется ситуация тем, что заборы не обязательно должны быть видимы. Мертвые как известно те, кто не видят (сравни «зажмурившийся», «жмурки»), в условиях отсутствия доступа к технологиям, приложениям, плагинам, сети - мы выключены из мира коммуникации, а обладая доступам к технологии мы и на сам город смотрим как сквозь забор, сквозь цифровые приложения посредством которые улицы становятся приложениям к приложениям. Граффити, растущие на заборах, были вторжением конкретного опыта в стихию абстракции, криком, расцветшим в красках. Но как быть с теми заборами, которые возводятся нашим действием или точнее нашим коллективным бездействием - в сетях и цифре? Власть забора обнаруживается в том, чтобы обращать любое действие - в бездействие. И нам нужно сообщать выработать стратегии сопротивления этому молчаливому насилию. По мысли автора, мы недостаточно понимаем какой, каким и где должен быть забор. У нас нет развитых экологических моделей. «Кричащая реклама, тесноты архитектурных плоскостей, геометрия антропогенного пейзажа убивают «воздух» города, пространство, в котором нет места трехмерным скульптурам и человеческому телу» (с. 103). Широкий анализ социальный среды и перформативных художественных и философских жестов, произведенный в книге призван если не исправить, то, по крайней мере, привлечь внимание к этому недостатку, а также наметить пути решения. Забор должен быть не просто агентом эроса, полемоса и танатоса - он должен стать фигурой логоса.

\section{Забор внимания}

Редко, когда автору удается настолько бережно очистить от привычек, автоматизмов, от инерции повседневности, свой объект, освободить его от незаметности и представить с должной остротой концептуальной выраженности. Еще реже удается завлечь в игру концептов, сюжетов, образов читателя, который, казалось бы, уже все видел, все читал и от всего устал. Выделить предмет из безразличия, ввести в курс дела, встревожить темой и снабдить соответствующими техниками безопасности (от художественных практик до иронических приемов), чтобы концептуальная проблема не перешла в экзистенциальное навязчивое состояние - это у автора получается лучше всего и книга, покорит даже тех читателей... которые на забор в лучшем случае плевали.

\section{Список литературы}

Konings, M. (2015). The Emotional Logic of Capitalism: What Progressives Have Missed. Stanford, CA: Stanford University Press.

McKenna, T. (1993). Food of the Gods: The Search for the Original Tree of Knowledge. A Radical History of Plants, Drugs, and Human Evolution. New York: Bantam. 
Shapin, S., \& Schaffer, S. (1985). Leviathan and the air-pump: Hobbes, Boyle, and the experimental life. Princeton, New Jersey.

Гегель, Г. В. Ф. (1968). Эстетика. В 4-х томах. Том 1. Москва: Искусство.

Делёз, Ж. (2004). Переговоры. 1972-1990. Санкт-Петербург: Наука.

Джеймисон, Ф. (2014). Постмодернизм и общество потребления. В Марксизм и интерпретация культуры (сс. 288-309). Москва; Екатеринбург: Кабинетный учёный.

Дюби, Ж. (2002). Время соборов. Искусство и общество 980-1420 годов. Москва: Ладомир.

Канторович, Э. (2015). Два тела короля. Исследование по средневековой политической теологии. Москва: Издательство Института Гайдара.

Кардини, Ф. (1987). Истоки средневекового рыщарства. Москва: Прогресс.

Карьер, Ж.-К., \& Эко, У. (2010). Не надейтесь избавиться от книг. Санкт-Петербург: Симпозиум.

Киттлер, Ф. (2009). Оптические медиа. Берлинские лекции 1999 г. (О. Никифоров \& Б. Скуратов, Пер.). Москва: Логос; Гнозис.

Латур, Б. (2017). Визуализация и познание: Изображая вещи вместе. Логос, 27(2), 95-156.

Лихачев, Д. С. (1998). Поэзия садов: К семантике садово-парковых стилей. Сад как текст. Москва: Согласие.

Плутарх. (1961). Сравнительные жизнеописания. В 3-х томах. Том І. Москва: Издательство Академии наук СССР.

Ренан, Э. (1990). Жизнъ Иисуса. Москва: Слово.

\section{References}

Cardini, F. (1987). The Origins of Medieval Chivalry. Moscow: Progress. (In Russian).

Carrier, J.-C., \& Eco, W. (2010). Don't hope to get rid of the books. St. Petersburg: Symposium. (In Russian).

Deleuze, J. (2004). Negotiations. 1972-1990. St. Petersburg: Nauka. (In Russian).

Duby, J. (2002). Time of the Cathedrals. Art and Society 980-1420. Moscow: Ladomir. (In Russian).

Hegel, G. W. F. (1968). Aesthetics. In four volumes. Volume 1. Moscow: Art. (In Russian).

Jamieson, F. (2014). Postmodernism and the Consumer Society. In Marxism and the Interpretation of Culture (pp. 288-309). Moscow; Yekaterinburg: Cabinet Scientist. (In Russian).

Kantorovich, E. (2015). The Two Bodies of the King. A Study in Medieval Political Theology. Moscow: Gaidar Institute Press. (In Russian).

Kittler, F. (2009). Optical Media. Berlin Lectures 1999. (O. Nikiforov \& B. Skuratov, Trans.). Moscow: Logos; Gnosis.. (In Russian).

Konings, M. (2015). The Emotional Logic of Capitalism: What Progressives Have Missed. Stanford, CA: Stanford University Press.

Latour, B. (2017). Visualization and cognition: Picturing things together. Logos, 27(2), 95-156. (In Russian). 
Likhachev, D. S. (1998). The Poetry of Gardens: Toward the Semantics of Garden and Garden Styles. The Garden as Text. Moscow: Soglasiye. (In Russian).

McKenna, T. (1993). Food of the Gods: The Search for the Original Tree of Knowledge. A Radical History of Plants, Drugs, and Human Evolution. New York: Bantam.

Plutarch. (1961). Comparative Biographies. In three volumes. Volume I. Moscow: Publishing House of the Academy of Sciences of the USSR. (In Russian).

Renan, E. (1990). The Life of Jesus. Moscow: Slovo. (In Russian).

Shapin, S., \& Schaffer, S. (1985). Leviathan and the air-pump: Hobbes, Boyle, and the experimental life. Princeton, New Jersey. 